\title{
Diálogos modales en medio de una Última Sena: Jordi Claramonte y Feliza Bursztyn
}

\section{Artículo de reflexión}

Adryan Fabrizio Pineda Repizo

Universidad Autónoma de Colombia faospace@gmail.com

Recibido: 13 de diciembre de 2018

Aprobado: 25 de diciembre de 2018

Cómo citar este artículo: Pineda Repizo, Adryan Fabrizio (2020). Diálogos modales en medio de una Última Sena: Jordi Claramonte y Feliza Bursztyn. Calle 14: revista de investigación en el campo del arte 15(27). pp. 40-55. DOI: https://doi.org/10.14483/21450706.15408

\section{(c) (1)}

https://creativecommons.org/licenses/by/4.0/deed.es 


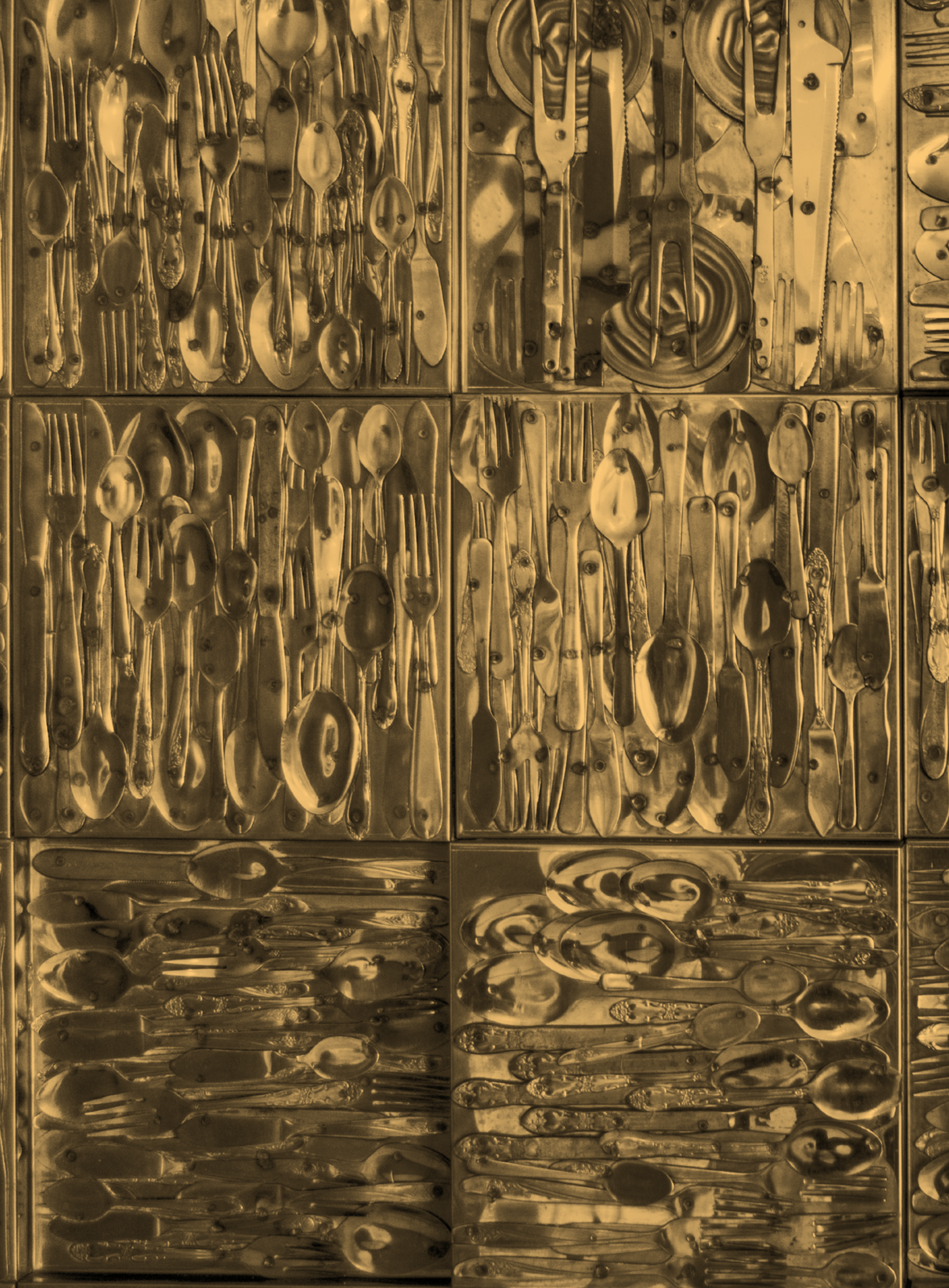


Diálogos modales en medio de una Última Sena: Jordi Claramonte y Feliza Bursztyn

\begin{abstract}
Resumen
A partir de las categorías modales de la teoría de la estética modal de Jordi Claramonte, este texto expone un modo de aproximación a la identificación de relaciones modales como ejes de análisis de una obra de arte. Para tal fin, se plantea un diálogo con la obra La Última Sena de la escultora colombiana Feliza Bursztyn. Esta obra permite ilustrar las tensiones entre lo disposicional y lo repertorial como constitutivos de lo artístico y de lo estético.
\end{abstract}

\title{
Palabras clave
}

Estética modal; Feliza Bursztyn; Jordi Claramonte

\section{Modal Dialogues in the Middle of La Última Sena: Jordi Claramonte and Feliza Bursztyn}

\section{Abstract}

Based on the modal categories of Jordi Claramonte's modal aesthetic theory, this text exposes a way of approaching the identification of modal relationships as axes of analysis of a work of art. To this end, a dialogue is proposed with La Última Sena of Colombian sculptor Feliza Bursztyn. This work allows to illustrate the tensions between the dispositional and that which belongs to the repertoire as constitutive elements of the artistic and the aesthetic reality.

\section{Keywords}

Modal aesthetics; Feliza Bursztyn; Jordi Claramonte

Dialogues modaux au milieu de La Ultima Sena : Jordi Claramonte et Feliza Bursztyn

\section{Résumé}

Basé sur les catégories modales de la théorie esthétique modale de Jordi Claramonte, cet article expose une façon d'aborder l'identification des relations modales en tant qu'axes d'analyse d'une œuvre d'art. À cette fin, un dialogue est proposé avec La Última Sena de la sculpteure colombienne Feliza Bursztyn. Cet œuvre permet d'illustrer les tensions entre le dispositionnel et ce qui appartient au répertoire en tant que constitutives de la réalité artistique et esthétique.

\section{Mots clés}

Esthétique modale ; Feliza Bursztyn ; Jordi Claramonte

\section{Diálogos Modais no Médio de La Última Sena: Jordi Claramonte e Feliza Bursztyn}

\section{Resumo}

Com base nas categorias modais da teoria estética modal de Jordi Claramonte, este texto expõe um modo de abordar a identificação de relações modais como eixos de análise de uma obra de arte. Para este fim, um diálogo é proposto com La Última Sena da escultora colombiana Feliza Bursztyn. Este trabalho permite ilustrar as tensões entre o disposional e o repertórial como constitutivos da realidade artística e estética.

\section{Palavras-chave}

Estética modal; Feliza Bursztyn; Jordi Claramonte 


\section{Maillallachiska}

Kallariskamanda chi kategoria Modalkuna teoría chi estética modalkuna Jordi Claramontemanda chi kilkaska kauachimi imasa kaillaiaska risingapa chi relación modal imasami kauari sug obra de arte.chipak churarinmi rimanakui chi obrava kati mikuikunamanda chi escultura Colombiana Feliza Bursztyn. Kai obrak sakinmi kauangapa tensionkuna disposicionmanda i repertorial imasa constitutivos artistikomanda i este esteticomanda.

\section{Rimangapa Ministidukuna}

Estética modal; Feliza Bursztyn; Jordi Claramonte 


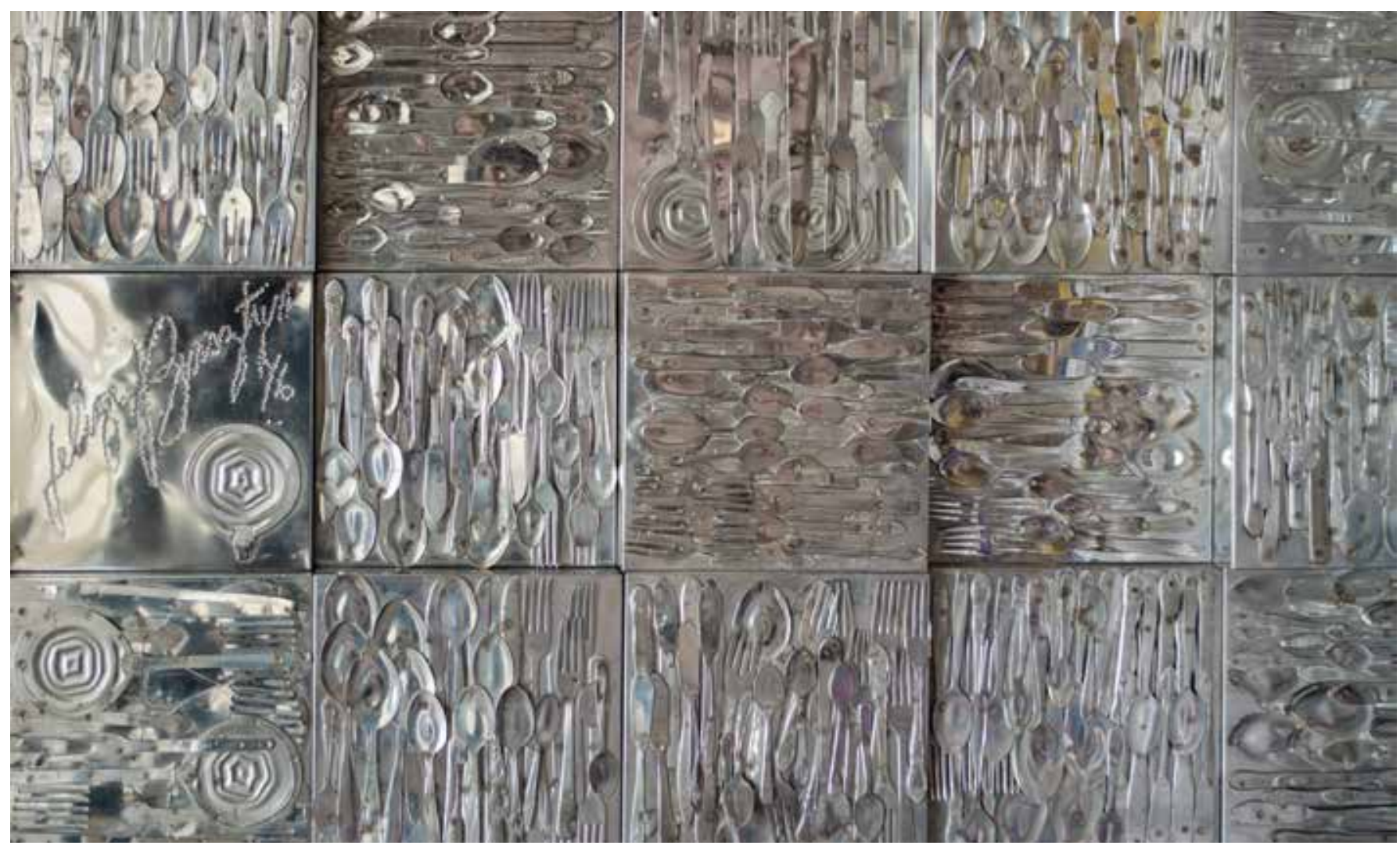

La última Sena (1975-1976). Feliza Bursztyn. Fotografía de Jesús Holmes Muñoz.

Tal vez, lo mejor sea ser claro y directo. Las letras que tienen frente a ustedes son resultado de un proyecto en desarrollo ${ }^{1}$ que ha surgido de interrogar el lugar y significación del objeto de uso cotidiano en la obra de arte. En general, los objetos de uso cotidiano son marcas materiales de una estética ligada al hacer y al habitar que es constitutiva de nuestra experiencia diaria. Pero cuando un objeto de ese escenario es llevado al trabajo artístico - apropiado, transformado, reutilizado- se evidencian unas potencialidades de significación que usualmente permanecen desapercibidas en la experiencia cotidiana. Qué emerge, qué se construye, qué se evidencia en esa poética artística es la inquietud que no me deja en paz y que ha suscitado esta reflexión. Sin embargo, uno de los cuestionamientos más difíciles de resolver en la metodología de este proyecto es ¿cómo establecer el marco de relaciones de significación que se pueden explorar en cada obra? ¿Cuál es el límite, la coordenada o el rango en el que esas relaciones ponen a jugar los signos? ¿Cómo contener el impulso semiósico ilimitado? Se necesita una aproximación relacional

1 Proyecto Extrañamientos del objeto de uso en el arte contemporáneo de Colombia: lo provincial, lo espectral y lo irreverente, del programa de Doctorado en Arte y Arquitectura de la Universidad Nacional de Colombia. con un conjunto de categorías relacionales ellas mismas que tengan un alcance definido.

Y confieso que hay algo en la propuesta de la estética modal de Jordi Claramonte que me resulta particularmente sugestivo. A veces la mejor teoría no es solamente la que tiene un gran potencial explicativo, sino aquella que es capaz de despertar el pensar, de suscitar asociaciones inesperadas. Su libro, titulado sin más Estética modal, y de fresca publicación (2016), presenta una trama conceptual que cumple con esta invitación. A partir de lo que él denomina 'categorías modales' es posible establecer un tejido conceptual que reconozca las tensiones constitutivas de lo estético. Con todo, extrañé en el libro una lectura de una obra de arte particular; ello es explicable, empero, en la medida en que Claramonte no propone una teoría del arte, sino de la estética, entendida como ese tejido común que une la vida a sus formas culturales de existencia. Quisiera, por mi parte, abrir unos pensamientos modales en diálogo con la estética modal en torno a una de esas particulares obras que tanto me llaman la atención.

En 1976 la escultora colombiana Feliza Bursztyn elaboró un mural a disponer en el Centro de Hotelería, Turismo y Alimentos del SENA, en el centro de Bogotá, compuesto 
por 12.000 cubiertos de mesa y cocina distribuidos en 276 paneles cuidadosamente compuestos, cada uno, según su propia densidad y soldadura. La obra se titulaba La Última Sena. La multiplicidad de cubiertos apiñados, yuxtapuestos, en líneas verticales y horizontales, se confrontan con la luz y posición de la mirada para dar un caleidoscopio de brillos metalizados de arista a arista, arriba abajo y derecha a izquierda, de la pared. Apelemos ahora a unas definiciones. En Estética modal, las categorías modales remiten a modos de hacer, a poéticas (2016, p. 23) en el mundo que para tener lugar requieren al menos tres maneras de ser: un repertorio de valores que guardan la coherencia y estabilidad formal, una disposición a la experimentación y el juego y un despliegue efectivo de su comparecencia en el mundo. Estos tres modos (repertorialidad, disposicionalidad, paisaje) entran en relaciones de armonía y de conflicto, no solo en el arte, sino en lo "procomún", esto es, la vida misma de la cultura, la sociedad y la vida política. ${ }^{2}$ De esta manera, "ningún modo de relación quedaría enteramente decantado de uno o del otro lado, sino que más bien podíamos entender cualquier poética, cualquier modo de relación como una concreta -aunque variable - proporción, una aleación de inteligencia cristalizada e inteligencia fluida, una mezcla en la que quizás predominaría más el cuidado de un repertorio ya relativamente, logrado o quizás las variaciones disposicionales que podían aún estarlo constituyendo" (2016, p. 26). Y, a la vez, dicha proporción entre repertorios y disposiciones se establece en una relación transformadora con el mundo efectivo de las prácticas sociales. Con estos lentes, "necesidad" y "contingencia" remiten al modo de la repertorialidad, al hecho de que algo es necesario por razones de coherencia; lo "posible" y lo "imposible" son modulaciones de la categoría de lo disposicional, lo que está en nuestros poderes hacer o al alcance de nuestras disposiciones; finalmente, lo "efectivo" y lo "inefectivo" son los modos que forman

2 El término "procomún" es usado por Claramonte como el orden que comparten lo estético y lo político en la vida social. De hecho, lo común, aquello que damos por sentado y que configura el sentido de lo cotidiano, es tanto un repertorio axiológico de lo estético como un modo de organización de lo sensible y lo efectivo en el mundo social. Y es precisamente esta base común la que inspira la dimensión política de la estética modal, pues el conocimiento de lo repertorial no puede limitarse a una base de conocimiento de las formas culturales o artísticas de sentido, sus patrones comunes, sino que estos mismos constituyen la posibilidad de lo posible, de lo disposicional, de las variaciones tanto en lo estético como en la vida misma, y con ello, en la transformación de lo político. En el texto Procomún y arte, Claramonte identifica estas posibilidades como las tensiones modales que se evidencian en la transformación del sujeto moderno a una apertura de lo subjetivo en lo comunitario: la categoría de paisaje como el modo en que, de hecho, se está dando. La cuestión es que estas categorías se entienden modales en tanto son al mismo tiempo en lo que hay, son tres modos del ser: "lo posible aquí ya no podía ser considerado como un estado del ente al lado del ser efectivo, sino "como un momento modal contenido y supuesto en el ser efectivo» como la muerte está supuesta y contenida en el ser vivo, coincidiendo con él en la extensión pero no, obviamente, en el momento ni en la composición de relaciones en que se despliega" (2016, p. 306).

Pero esta vinculación es autónoma, es decir, da cuenta de los modos de relación mediante los cuales se logra un equilibrio dinámico, sistémico, una composición de nosotros como humanos, articulando el juego entre caos y orden, entre lo posible y lo necesario. De ahí la alusión a la autopoiesis: es una autonomía efectiva, compleja, fluctuante definida por las oscilaciones entre lo necesario y lo posible que muestra que la autonomía es una propiedad de los sistemas complejos (2016, p. 310). Las teorías de la complejidad, precisamente, permiten entender los procesos de autoorganización en sistemas no-lineales o sistemas abiertos, como la tendencia al equilibrio en virtud de las relaciones de inclusión y exclusión, de orden y posibilidad, y la manera en que nuevos elementos dan lugar a relaciones que pueden llevar a un nuevo estado del sistema. Para Claramonte, la experiencia estética funciona de manera similar en la medida en que en su performatividad se confronta con elementos con los que no contaba previamente; supone la relación entre una sensibilidad afectada por otras experiencias que transforman el sistema.

Diríase que el verdadero "sujeto" en la mayoría de las poéticas no es el individuo que materializa o ejecuta la "obra de arte" sino el particular "modo de relación" en función del cual se construye y recibe la obra". Y más adelante afirma: "más que reproducir o estetizar colectividades o comunidades nos hemos centrado en la investigación de los repertorios de recursos "modales" fundamentalmente comunes cuya reposición otorgaba a cualesquiera colectividades un mayor grado de complejidad y agencia. [...] En unos y otros casos no se trata, no se ha tratado nunca, como hemos adelantado de alguna forma, de reforzar grupos instituidos sino de dotar de fuerzas y herramientas a lo instituyente. [...] Sostenemos que cabe inves tigar la base común, el repertorio - abierto y mutante- de "patterns", de modos de relación, que sustentan la creatividad artística y social y sostenemos que debemos luchar por que lo común refuerce lo común (Claramonte, 2007).

En la perspectiva de la estética modal, en consecuencia, las poéticas artísticas tienen la posibilidad de dinamizar las tensiones entre lo repertorial y lo disposicional para transformar, no solo lo artístico, sino la vida misma de lo procomún. 
Asimismo, podemos hablar de sistemas alejados del equilibrio como aquellos que solo pueden existir en conjunción con su entorno, como sucede con los materiales estéticos que nunca pueden considerarse por completo desgajados de su momento de producción y/o recepción social e histórica, de modo que en ellos la disipación de energía y materia que suele asociarse a la noción de pérdida y evolución hacia el desorden se convierte en fuente de un orden que solo puede emerger de la autoorganización, de la necesidad interna de cada poética (2016, p. 311).

De vuelta a la obra: ¿qué es repertorial y disposicional en esta cosa que llamamos la obra de arte La última Sena? Fijemos unos puntos de vista. La pregunta no es por La Obra de Arte, el genérico abstracto de un conjunto de cosas singulares. Se trata de esa cosa que porta el título La Última Sena; eso es el punto de partida efectivo (recordemos: "algo será necesario o posible siempre en relación con algo efectivo o inefectivo, aunque por supuesto ese estar en relación pueda llevar a transformar o incluso suprimir y reemplazar lo que venía siendo efectivo. Lo efectivo no es intocable, pero es siempre aquello de lo que debemos partir, sea para confirmarlo o sea para quebrarle el espinazo" (2016, p. 94). Esto es relevante porque ubica la mirada en el hacer que se compromete en esta cosa dada a la experiencia de quien a ella se aproxima. Pero entonces, ¿qué se modula en esta cosa? Hay una variedad de tensiones internas y externas a la obra que permiten ver la manera en que a partir de las categorías de la estética modal es posible acercarse a responder el interrogante metodológico.

Lo primero, el objeto de uso. Lo que hay es un conjunto perceptualmente inabarcable de un tipo particular de objeto de uso, unos cubiertos: cucharas, tenedores, cuchillos y espátulas de mesa y cocina. Con este punto en mente ya ha empezado nuestro diálogo modal. ¿Qué son los cubiertos? Si seguimos las huellas dejadas por el Norbert Elías del Proceso de la civilización (2011, pp. 160-168), los cubiertos son functores de organización social. Establecen un orden, una manera de hacer en la mesa, un código de conducta inquebrantable a riesgo de caer en la inmoralidad, un conjunto de hábitos que cada quien debe asimilar y normalizar desde la tierna infancia. Sus características morfológicas nos parecen hoy elementales, pero lo cierto es que implicaron una transformación tanto de la relación con el procesamiento de los alimentos y su disposición a la mesa -otro objeto de uso normalizador-, como de la etiqueta de socialización y distinción social, habitus, citando a Bourdieu (1999), tan incorporados en el cuerpo mismo que su carencia sume al individuo en el salvajismo. Los cubiertos son claros casos de necesidad silenciosa en la cotidianidad que garantizan el buen funcionamiento de la civilización.

Pero ¿y qué pasa cuando se sacan de la mesa y se yuxtaponen, unos casi encima de otros, en el mural de Bursztyn? No hace mucho mi pequeña Emma Sophia, con dos aventureros años, sacó, regó, "desordenó" los cubiertos de la casa con la mayor libertad y confianza posible, sin respeto alguno por su solemnidad, solo para luego arrumarlos, sabiamente, unos sobre otros, en su pequeña caja de juguetes y, luego, fascinada, explotar de alegría y compartir su hazaña conmigo. Allí, a lo Feliza, los cubiertos gemían unos contra otros el saboteo de su función policial, a la vez que demostraban algo diferente: tenían su propio brillo, eran incluso bellos como cosas radiantes y resistentes al más duro trato, dignos de ser vistos y conservados de otra manera. Pero nunca dejaron de ser los cubiertos, la performatividad de la práctica social corporizada en ellos y en mí - que organizan mi mesa y actividad familiar y, por supuesto, me compelen a re-organizar el cubertero- no desapareció, sino que entró en tensión y co-construcción con un ojo de lo posible - probablemente, parodiando a Rancière (2009), hay un régimen estético en la hija diferente al régimen ético del padre. Podría decirse que como objetos de uso, su carácter normativo y su ineludible necesidad en el hogar no excluyen lo posible, esto es, el hecho de que en la mano de quien come, y más aún de quien no los usa para comer, también pierden su rigor, dependiendo de la gracia del uso en la cotidianidad, de la inventiva popular a que en un momento dado pudieran someterse e, incluso, o mejor, sin duda, de la lúdica de re-creativas de diseño que puedan otorgar variabilidad a la sempiterna práctica de comer a la mesa, por burguesa que nos pueda parecer (aunque nada fácil cuando hablamos de cubiertos, pues i¿cómo se re-diseña una cuchara?!). En la obra de Bursztyn los cubiertos no dejan de ser lo que son, aún si nadie ve la obra por la invaluable tarea de cuidar de tan gran número de ellos, ni si la crítica de arte es ciega al hecho de que lo que hay es, de hecho, cubiertos. La apertura al juego, ya en el otro uso del objeto, ya en sus variaciones particulares de una cuchara a otra, señalan la presencia en el tipo de objeto de uso mismo de lo disposicional y que éste pertenece, antes que a la obra, al objeto mismo.

Pero en la obra hay aún mucho más. Segundo: la artista-objeto. iSon 12.000 cubiertos! iSi lo intentara, no sé si me perdería en el 100 o en el 1.000! Todos brillantes, pulidos, apenas visibles los puntos de soldadura, $y, \sin$ 
embargo, alineados en extremo. Es casi compulsiva, obsesa la manera en que Feliza ubica uno a uno los 12.000 cubiertos mientras va llenando cada uno de los 276 paneles de 40 × $40 \mathrm{~cm}$ - sin mencionar luego la limpieza y pulida de cada punto de soldadura (dos por cubierto, 24.000 esfuerzos). ¿No hay ahí otra necesidad de coherencia, de sentido, de repertorialidad? Si la anterior remitía al nombre de la cosa <cubierto>, aquí lo que debe ser se expresa en el detalle enfermizo del hacer de Bursztyn. Es inevitable imaginarse las rodillas en el piso y la mirada pérdida en el metal, puliendo su preciado tesoro, al mejor estilo de Mordor. ¿Por qué no terminó en un manicomio después de semejante empresa? ¿No señala acaso el síntoma de una conducta digna de la más estricta medicalización?

Pero precisamente la locura de esta fuerza centrípeta que puede terminar en el ensimismamiento de una fascinación esquizoide se tiene que confrontar con la potencia de salida, de fuga, diría Deleuze (2006). La captura del trabajo de orden, alineación, atención obsesa se confronta con lo posible de, a la vez, la intensidad deseante: el perseguir sin freno la multiplicidad, perder el objeto concreto para abrir la magnitud de lo centrífugo, la dilución de lo particular en la vibración del brillo argentado; en últimas, el cuerpo sin órganos que se fuga en el ígneo acero. Si todo el repertorio de la acción de Bursztyn fuera la obsesión del uno a uno perfectamente alineados, la obra no podría brillar; la magnitud de cubiertos brilla en tanto ha incorporado el flujo deseante de Feliza en el cuerpo que toca, ubica, suelda, pule, se pierde en la intensidad del hacer hecho obra. En esta pulsión se encuentra lo que no puede ser capturado por el ensimismamiento esquizoide, pero sin el cual no podría expulsar las intensidades de la relación del cuerpo con cada objeto y su multiplicidad. iGoza tu síntoma!, diría Zizek (2011) a Bursztyn, asume el riesgo de la caída esquizoide, vivencia la pulsión constitutiva de tu propia producción de sí. Es por ello que la obra termina como expectativa de mural, expuesto y sumergido en la luz y el movimiento, el cambio de posición, donde el flujo que se balancea hacia la disposicionalidad retorna, efectivamente, sin caer en la locura a la materialidad de lo que se ha hecho cuerpo.

Tercero: la obra a la vista. En un valiente catálogo, Susie Hodge (2014) presenta cien obras de arte contemporáneo que han suscitado hostilidad o sequedad por parte del público y la crítica en un volumen titulado Por qué un niño de cinco años no pudo haber hecho esto. La carencia de una exposición argumentativa no elude lo sugestivo que resulta este título. Asumamos que, a pesar de la abierta irresponsabilidad que supone, la niña Feliza sí pudo recolectar, ensamblar con soldadura y armar los paneles de La última Sena. ¿Haría alguna diferencia? Para autores como Danto (1964) o Dickie (1997), tan poco estimados por Claramonte, habría un conflicto allí: desde el punto de vista de la cosa sensible, no habría diferencia alguna; pero desde el punto de vista del "mundo del arte" o las "instituciones del arte" la diferencia sería radical, pues, en términos toscos, Bursztyn es un agente del mundo del arte, la niña, no.

Hay dos cosas que se evidencian de este diagnóstico. Por un lado, la conclusión de Danto o Dickie solo concibe el arte como una isla que no (se) alimenta (de) lo estético (ambas vías son ciertas); se reduce a un juego que, en términos modales, cae en la inefectividad: las relaciones son tan simplificadas a un asunto de pertenencia o no, que realmente podrían o no llegar a ser. Pero, por otro lado, el reconocimiento de lo institucional es, de hecho, efectivo. Bursztyn juega con este marco de posibilidad y allí es donde tiene sentido poner en tensión los repertorios que alberga con las disposiciones de su propia poética. Pero lo institucional no puede reducirse a los "agentes" del "mundo del arte", sino que ha de alcanzar, por efectos relacionales, toda la dimensión de la cultura y la vida en común.

Ello nos lleva al reconocimiento de que en el campo de lo estético no hay arte sin un público que pueda disfrutarlo, experimentarlo e, incluso, repudiarlo. Ese público está compuesto por un conjunto indistinto de individuos que han contado con el capital simbólico necesario para exponerse a esa experiencia. Pero ello no quiere decir que sea necesariamente un conjunto excluyente. Como miembros de una cultura, en la palabra "arte" resuena una historia y un marco de referencias que incluye bodegones, postales de Van Gogh, la película de Picasso, la boina del poeta, el museo de la séptima, las artesanías boyacenses y, últimamente, según el gobernador de Antioquia, las composiciones de Maluma, entre otras muchas cosas. Claramonte a veces ilustra con demasiado rigor lo necesario conforme al repertorio de lo clásico o lo canónico en la historia del arte, pero podría - o incluso debería - decirse que, antes que necesario, el conjunto multiforme de cosas que llamamos arte es constitutivo de lo efectivo para el arte. De ahí que una artista tenga a su disposición el depósito de una chatarrería y que, a la vez, haga "escultura". Pero también que el público se acerque a esta obra y reaccione con una experiencia de extrañamiento (o en términos de Claramonte, de desacoplamiento): veo las cucharas, tenedores y cuchillos, son las mismas 


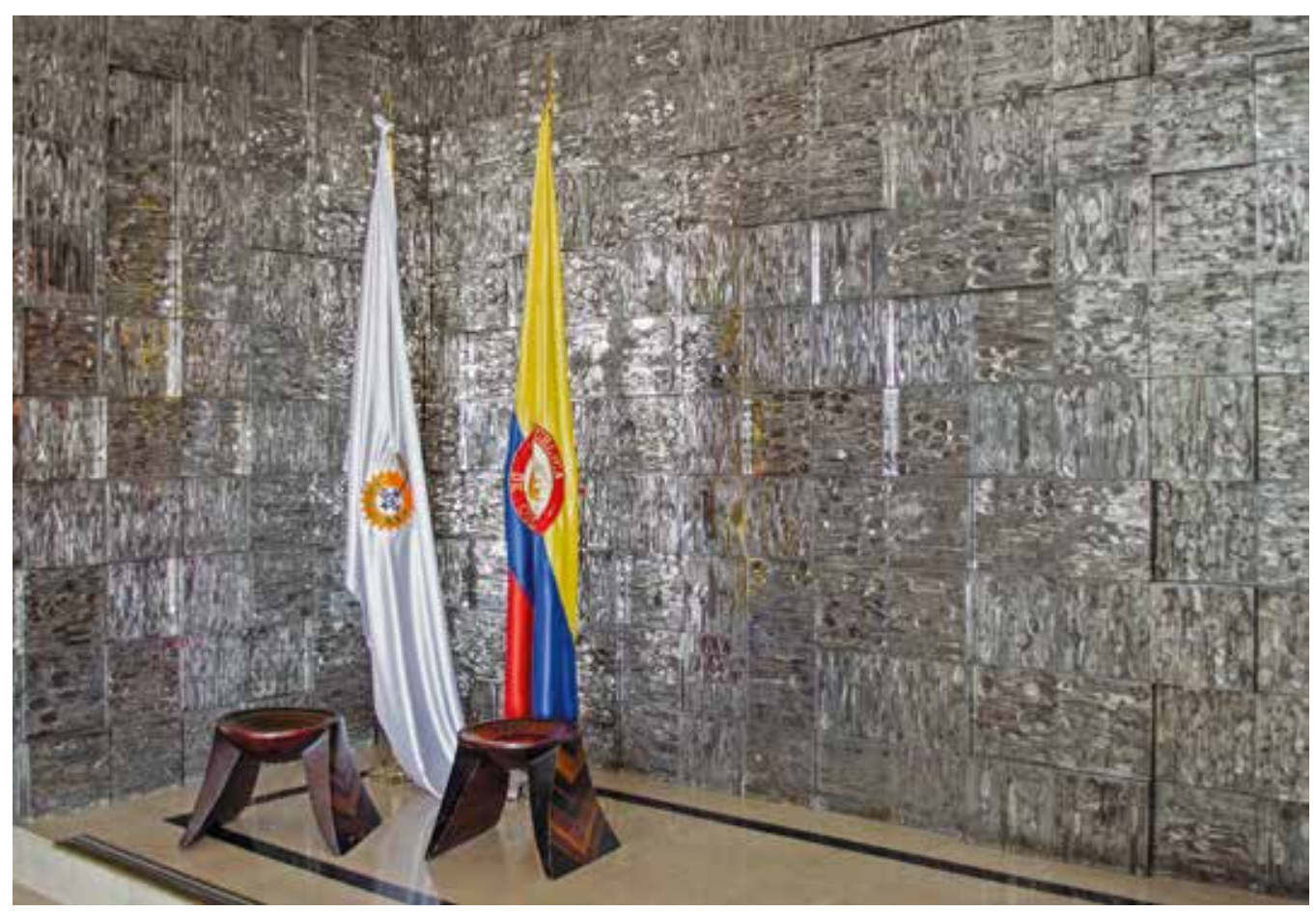

La última cena (1975-1976). Feliza Bursztyn. Fotografía: Jesús Holmes Muñoz.

que reconozco (se impone, necesariamente, el nombre y su saber de la cosa), pero ya no son cubiertos ni pueden ser usados (hay una variación disposicional en mi mirada) y están aglutinados en unos paneles que componen un mural en un lugar de exposición (efectivamente, hay que ver esa cosa, según dicen, como una obra de arte). La experiencia de extrañamiento es un momento lucidamente modal, pues desacopla los repertorios de lo que como público usualmente aceptamos como artístico y, a la vez, nos lleva a abrirnos a su redistribución y asimilación:

En términos modales lo llamativo del caso es que, en el primer paso, el del extrañamiento propiamente dicho, lo que se da es una quiebra de la repertorialidad vigente y una apertura hacia lo disposicional que abra el campo de lo posible, de lo que podemos hacer y comprender con lo que hay. A su vez, en el segundo paso, al que Sklovski llama artistización, se impone una relativa clausura de lo disposicional - puesto que ya no se puede estar experimentando y jugando en «cualquier» dirección-y, consecuentemente, una tímida apertura hacia una nueva repertorialidad, una nueva gramática que mantenga fértil el dispositivo estético a través de su sofisticación y carga semiótica (Claramonte, 2016, p. 238).

Pero no es solo que el extrañamiento alimente el repertorio de lo artístico con una nueva categoría o "ismo", sino que recarga las nuevas relaciones de lo disposicional en la experiencia cotidiana de los individuos. Por ello, obras como la de Bursztyn otorgan a los individuos en su cultura la posibilidad de asociar la estética de las cosas, de las multitudes, de las reproducciones en masa y otorga otros códigos relacionales a las experiencias comunes: como individuos podemos llegar a decir "nunca más veré los cubiertos de la misma manera". Pero también puede suceder, como ciertamente ocurre, que para el público lo único que quede por decir sea "en ese arte ya no hay nada para mí". La obra se sume así en lo imposible, incapaz de conectarse con lo estético. De ahí que, para Claramonte, "toda experiencia estética es, al cabo, experiencia de un extrañamiento y de una reorientación, de un desacoplamiento y de la ilusión o la promesa de un reacoplamiento. El quehacer distintivo de cada artista consiste en gran medida en determinar la proporción, la ecuación que regula el equilibrio entre esas - y otras- polaridades" (Claramonte, 2016, p. 159).

Pero aquí se abre una cuarta lucha modal: lo artístico. Suele asumirse que una investigación en artes es una investigación en Historia del Arte, particularmente cuando de lo contemporáneo se trata. Como si ubicar la obra en la historia pudiera conjurar y dar sentido a la experiencia de extrañamiento. Un afán historicista que incluso autores como Noel Carroll (1999) defienden como el criterio de definición de lo artístico. Pero no 
se me ocurre, por paradójico que sea, algo más necesario e inefectivo a la vez. Necesario, pues se busca todo el repertorio de la historia para labrar un hilo narrativo claro y limpio en la que la obra es un punto más de la historia, dejando su aproximación sumida en el lenguaje privado; inefectivo, pues no se corresponde con lo que hay, con la experiencia vivida, ni responde a la multiplicidad de lo estético ni la potencia de lo poético. ¿Con qué mote narrativo, con qué 'ismo', se capturan las relaciones modales que juegan en la performatividad de la obra de Bursztyn? Precisamente el vicio de la historia del arte es convertir lo desacoplado, propio de lo relacional, en un punto de lo lineal:

[..] la inefectividad se revelará como una impotencia en el paisaje. Si entendemos los modos de relación efectivos bajo la categoría de lo complexo, quizás para pensar el modo de la inefectividad sea imprescindible estudiar la irrupción de lo simple. Se trataría entonces de pensar la inefectividad, o la muerte si se quiere, como una forma repentina o progresiva de simplificación. Así las cosas, podría bien decirse que lo inefectivo es el devenir simple de aquello que se muestra incomposible, que deja de producir complejidad, ciertos tipos de complejidad, quizás para pasar a producir otros" (Claramonte, 2016, p. 109).

Reducir la obra, sus objetos, sus brillos obsesos, el frenesí de su magnitud, el extrañamiento constitutivo, a una descripción de "arte colombiano de los setenta" es disolver la concreta proporción modal que le ha hecho ser.

En una dirección inversa, podemos leer en la obra de Bursztyn un hacer disposicional en su relación con la chatarra. La artista misma señaló lo siguiente:

En realidad, yo trabajé exactamente al contrario de como se concibe la escultura. Un escultor hace un dibujo de una forma, busca los materiales para esta forma y luego la ejecuta. Yo hago lo contrario. Me voy a los depósitos de chatarra, miro qué tienen y luego pienso qué voy a hacer con estos. No hay nada previo. Trabajo directamente sobre lo que tengo. Un procedimiento totalmente diferente a lo que se supone que debe ser la escultura (Citada por Osorio, 2010).

La chatarra pertenece al modo de lo contingente, el opuesto de lo necesario, y se cruza con lo imposible, lo que está fuera de la posibilidad. Pero es interesante que el hacer de la artista rescata lo desechado para incorporarlo en lo posible, el acto creativo, e introducirlo en lo artístico y, por su medio, en lo estético: lo hace participar tanto de la experiencia de extrañamiento que invita a ver de otra manera la propia materialidad, como de la necesaria lógica institucional del agente del arte en una obra para un edificio público. Solo habida cuenta de esta, su singularidad, cabe pensarla en relación con el repertorio de otras disposicionalidades en el campo del arte.

Ella no es la primera en recoger basura para hacer una obra de arte. A Germano Celant se le reconoce haber acuñado en 1967 el mote de arte povera. En uno de esos esfuerzos históricos por dar cuenta de la unidad de una década de la historia del arte, Thomas Crown señala:

[..] lo que Celant estaba proponiendo [frente a obras como las de Mario Merz] era otra noción, más indirecta, de pobreza: un deliberado empobrecimiento o vaciado de los códigos significativos preexistentes. En el arte americano, él se oponía tanto al pop como al minimalismo, porque ambos aceptaban los abstractos sistemas de producción y de distribución industrial que regían la conciencia moderna. Se trataba de sistemas que podían ser descritos verbalmente o representados artísticamente. La meta de los escultores del arte povera exigía, de hecho, eliminar el "re" de la "presentación", obligar al espectador a enfrentarse con nada que no sea él mismo" (2001, p. 147).

Las cosas se presentan desnudas y libres de distorsiones, sujetas no solo a su materialidad, sino también a su inevitable descomposición. Podría ser cuestionable que La última Sena pueda ser catalogada con el mote de povera, pero en parte la confrontación abierta con la materialidad y consigo mismo es, de hecho, una invitación presente en la obra. Con todo, hay aquí un gesto diferente al del arte povera. Los materiales no son orgánicos, no están sometidos a su descomposición, antes bien son insignes de durabilidad sin uso. La multiplicidad de los 12.000 cubiertos elude la razón crítica que Celant otorgaría a la recolección de objetos y basura. Pero tampoco es una obra minimalista enamorada de lo cotidiano. Al decir de Crown:

[..] en la preferencia de los minimalistas por los materiales cotidianos había una elocuencia lacónica que les acercaba a algunas poéticas del hombre corriente; es más, el rechazo del look artístico se consideró una manera de subvertir el espacio de la 
galería como mercado de bienes raros y preciosos; y las cualidades compositivas de anonimato, repetición e igualdad entre las partes siguieron proporcionando metáforas fundamentales al altruismo e igualitarismo políticos" (2001, p. 143).

Aunque establezca un diálogo con lo cotidiano, difícilmente se preocupa Bursztyn en esta obra por reconocer las "poéticas del hombre corriente" o la apariencia de lo artístico. Antes bien, la disposición en ella es hacia lo vital, y lo vital atravesado por el perfil de lo cómico, de lo burlesco, del doble sentido de lo visto y lo dicho, incluso desde el título de la obra: ¿es la última cena de quién, de los cubiertos, de quienes se quedaron sin cubiertos? ¿De quienes se inscribieron al SENA para aprender a dar de cenar? ¿Es otra solemne cena que se sirve en el SENA, que evoca la cena de Leonardo, pero a la vez multiplicada y, por ello, mismo diluida y dispersada? Los posibles juegos entre la cosa y lo dicho, los objetos y el título elegido por Bursztyn dan fe ya de un otro modo de ser del arte en Colombia, y probablemente en Latinoamérica, esto es, de un "paisaje complexo" distinto al de las corrientes que Crown categoriza entre Estados Unidos y Europa, una matriz particular que otorga sentido al ser de la obra y que está inserta en la trama equilibrada de la vida y la estética en nuestro contexto. Para Claramonte, el paisaje complexo tiene el carácter de lo atmosférico, abarca la posibilidad y estabilidad de las relaciones internas de un sistema y a la vez es más denso entre más cerca estén del núcleo; pero también, es por este paisaje complexo que una obra o una poética puede llegar a ser según las tensiones relacionales que establezca; lo cual, en otras palabra, significa que una obra o una poética no puede ser vista sino a la luz de la estética que le corresponde en el paisaje en el que se sitúa y en el complexo de relaciones en el que interactúa.

Lo posible se juega y se define entonces en relación con las disposiciones que cada complexo, cada sistema pone en juego. Bajo el modo de lo posible - como hemos sugerido - importa poco o nada si esas disposiciones se decantan en una forma objetivada o si esa forma objetivada viene a completar o a exacerbar otras; tan solo nos importará que determinada disposición o conjunto disposicional pueda vertebrarse y explorarse en su propio juego (Claramonte, 2016, p. 69).

Visto así, no se trata de que lo artístico en Europa y Estados Unidos no sea útil para pensar el arte en
Colombia; en tanto provea herramientas - como la mera comparación ya lo hace- para ver el arte, está defendida su utilidad. Pero, como en ocasiones se escucha, cuando se utilizan para cuestionar el origen y velocidad del arte en Colombia frente al 'panorama internacional', se desconoce y simplifica hasta la muerte la propia relacionalidad y, según la autopoiesis del paisaje, su autonomía y singularidad. Es precisamente esta singularidad la que, por ejemplo, Mari Carmen Ramírez (2004, p. 200) identifica con la noción de "estructura vital" en el arte constructivista latinoamericano, particularmente en el cono sur. Mientras que el constructivismo ruso objetivaba lo subjetivo para dar cuenta de la vida social, artistas como Joaquín TorresGarcía, Rhod Rothfuss o Hélio Oiticica hicieron de la estructura un modo de manifestación de lo vital subjetivo, de la búsqueda de una mirada cósmica o un origen primitivo mitopoiético de lo latinoamericano. El aporte particular de estos artistas latinoamericanos cercanos al constructivismo, según esta autora, yace en la noción de estructuras autorreferenciales de la obra de arte que comprometen la escatología misma de la región y que escapan al uso corriente y generalizado de las categorías historicistas.

En su propia línea de singularidad, la obra de Bursztyn tiene ese juego de la vitalidad latina que se desacopla de la Historia Oficial del Arte y dispone su propia lúdica en la experiencia de extrañamiento que provoca. Todos esos cubiertos están-ahí, para celebrar la posibilidad de ser y hacer con quien con ellos se confronta; y ciertamente ese juego está atravesado por el exceso y la seducción de lo cómico, incluso irónico, que permea nuestra cotidianidad, pero a la vez no hay una razón evidente de su efectividad, de su llegar a ser tal como da: es como si su lúdica misma compartiera ese carácter frugal y esa gratuidad con que se dispone, sin razón aparente, la existencia misma, la vitalidad de ir a una última cena, un último café, una última cerveza, y ya veremos mañana...

Quinto: del equilibrio. La figura que Claramonte utiliza a lo largo del libro, el atractor de Lorenz, captura la idea de que los modos de relación están en copresencia permanente, variando su proporción relativa y constituyendo la trama de lo efectivo. Con base en ello, la cultura sería un sistema abierto generado por esta constitutiva relación y, en su interior, lo estético y lo artístico son tensores constituyentes: "lo que llamamos cultura sería el correlato - condición y resultado a la vez- de una serie de modos de relación que traman las exploraciones y posibilidades de lo estético con los 


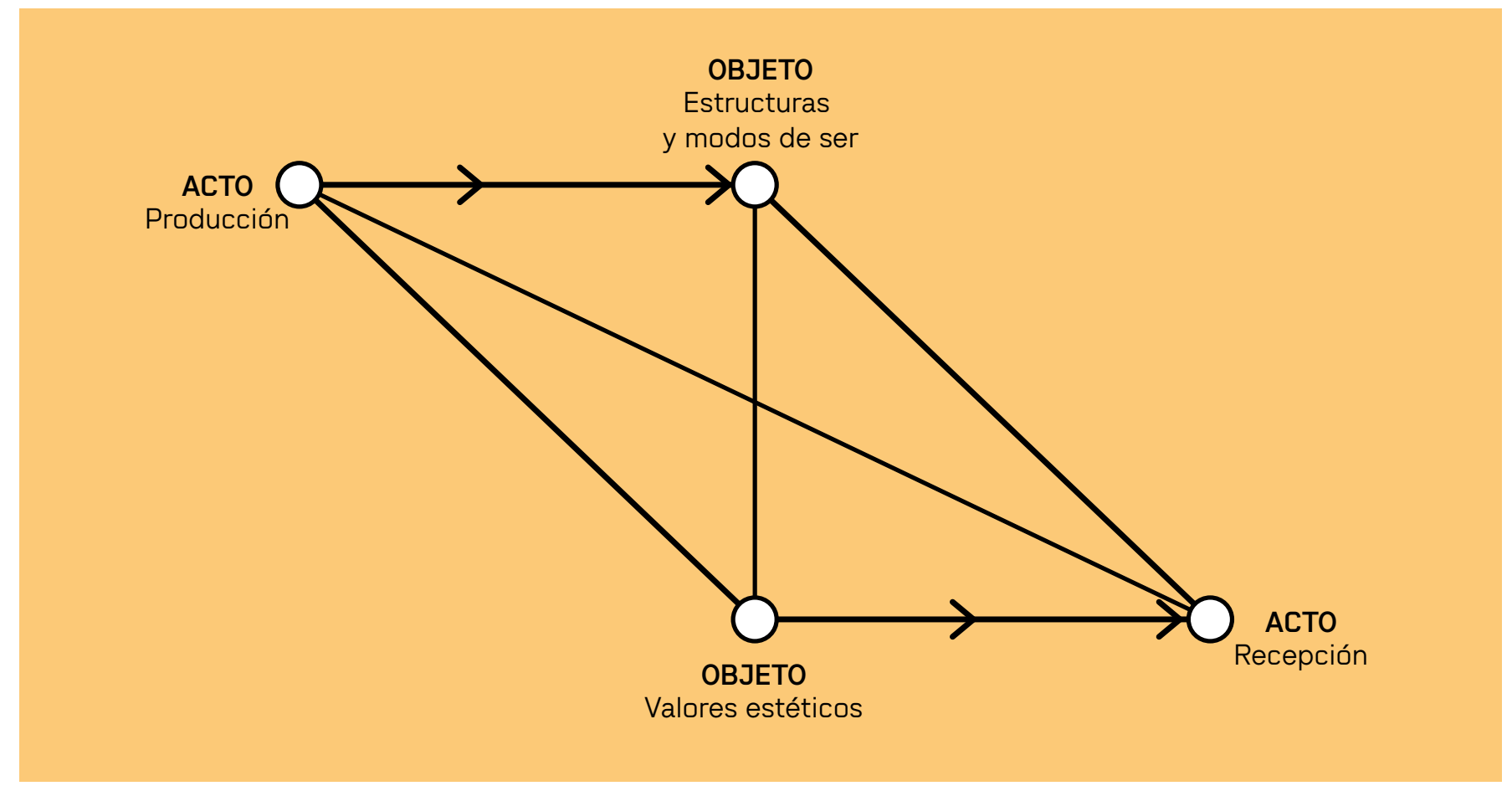

Gráfico 1: esquema de diamante según la estética modal

logros y las necesidades internas de lo artístico" (2016, p. 131). En esta imagen se introduce una inferencia implícita en principio contraintuitiva: si, respecto a la cultura y su devenir, lo estético pertenece al modo de lo disposicional con una lógica centrífuga, mientras que lo artístico pertenece al modo de lo repertorial con una lógica centrípeta, entonces lo artístico no es un generador de cambio, sino un consolidador de sentido. Es lo estético lo que mantiene abierto el sistema al introducir elementos de lo posible. Pero, en tanto modos relativos, se coproducen entre sí para efectuarse en lo cultural. Es por ello que la aproximación a la obra, en este caso La última Sena, no puede realizarse solamente con referencia a lo artístico sin con ello perder el potencial transformador de lo estético. Este no se encuentra en la Historia del Arte, sino en el "héroe de la cotidianidad", en el mundo común de la vida en el que se traman las posibilidades de existencia. Es en este escenario en el que se valida el lugar de la poética artística y en el que su hacer será causa de un nuevo estado del equilibrio dinámico del sistema.

Ahora bien, los cambios en los estados de un sistema abierto ponen en tensión, en la clásica definición de Bertalanffy (1989), la tendencia al orden (neguentropía) y la tendencia al caos y la incertidumbre (entropía). Las tensiones que hemos visto han sido reflejos de estas tensiones, y que Claramonte traduce, en la relatividad y pliegue entre lo repertorial y lo disposicional, como categorías de estética modal. Pues un sistema sin cambio es uno que está abocado a la muerte, a la simplificación de sus relaciones $o$ al agotamiento de sus procesos; solo puede ser renovado por la intromisión conflictiva de un elemento exterior: una proteína para una célula, un cambio de presión en las corrientes marinas, un migrante en una ciudad 0 , finalmente, una poética en un marco de lo artístico. Es precisamente esto lo que se manifiesta en la obra de Bursztyn, un elemento extraño, una variable nueva en la fórmula establecida que afecta la vivencia del objeto de uso (1), que desdobla el acto creativo (2), que desajusta la experiencia de la obra (3), que cuestiona su posición en el marco de lo artístico (4) y, ahora, que interroga por su capacidad de transformación dialéctica de lo estético -y un sexto efecto de equilibrio diría aun yo, como pronto plantearé.

En una perspectiva relacional (sistémica, compleja), no hay equilibrio dinámico si no hay disrupción o, en términos de nuestro autor, un quiasmo, pues el equilibrio no es el sosiego de lo conflictivo, sino la integración de la lucha como motor del sistema. Es por ello que la obra de Bursztyn es un caso de una manera en que se hace una incisión en lo artístico a fin de abrir posibilidades en lo estético. Y, con ello, crear un nuevo estado estético (diacrónico y sincrónico). Así como Peter Parker —en una 


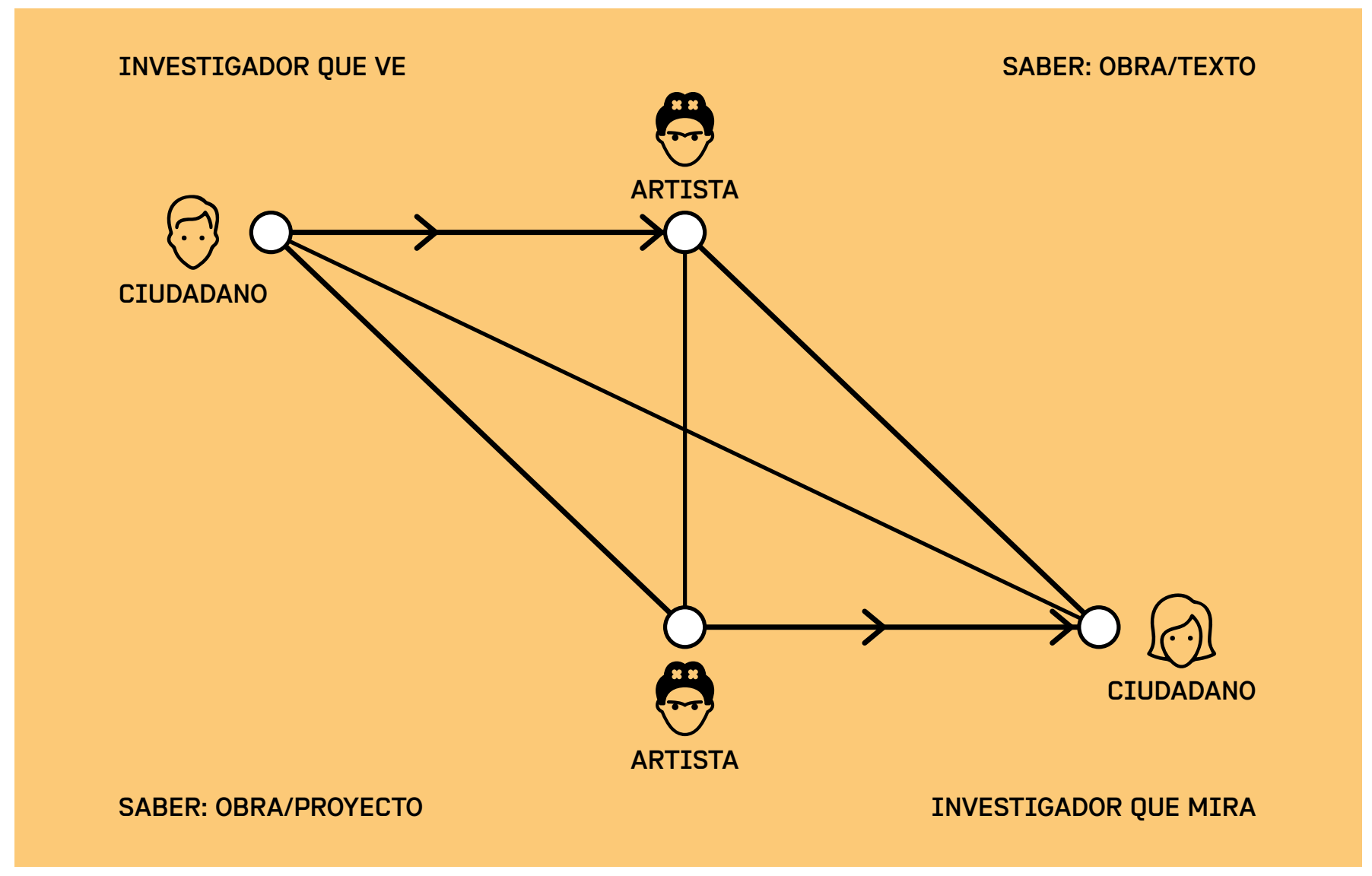

Gráfico 2: esquema diamante y experiencia del investigador

de las amadas analogías de Claramonte- nunca regresa a ser el mismo Peter después de haber sido picado por la araña, así lo estético que pasa por el quiasmo que logra producir obras como la de Bursztyn -atravesadas por la invitación al extrañamiento- no pueden sino desdoblarse y cambiar el orden de la existencia.

Como nos contara Merleau-Ponty, los quiasmos no suprimen aquello que había antes, sino que lo desdoblan, lo reflejan o más bien lo refractan produciendo otra cosa que tiene y no tiene que ver con la cosa que antes había. En adelante ya no podremos entender su existencia si no es bajo este doble carácter (Claramonte, 2016, p. 250).

Apliquemos la imagen del diamante de la estética modal (2016, p. 263) al quiasmo que nos interesa:

El acto artístico de Feliza produce, formal y materialmente, la obra titulada La última Sena con todas las tensiones relacionales que ya hemos sugerido. $Y, a$ la vez, a la luz de esas mismas tensiones, cuestiones de contenido, la obra in-corpora los valores estéticos requeridos para producir una sensibilidad dispuesta a la recepción de la obra. El acto de producción y el acto de recepción suponen un intercambio cruzado por la relación entre lo formal y material de la obra y los valores estéticos: una apertura en la sensibilidad que alimenta la posibilidad de una nueva producción. La cuestión es que lo estético estaría representado en las relaciones inscritas en este diamante, de modo que son co-presentes y co-productivas: la obra es resultado y generador del movimiento de lo estético, esto es, de la vida misma de los individuos en su tensión creativa disposicional y conservadora repertorial.

Finale: sexto: yo: lector/crítico/intérprete. Desde las primeras páginas de El animal que luego estoy si(gui)endo, Derrida (2008) expone un quiasmo estético que remite al sujeto y la mirada. Solo en la medida en que tropiezo con la mirada desnuda del gato que me ve, me siento y reconozco desnudo al salir de la ducha y reconozco su natural desnudez. La mirada de gato, lo sabía bien Lewis Carroll, tiene un poder de interpelación capaz de activar la performatividad del propio desdoblamiento: '¿Quién eres tú? ¿A cuál Alicia estoy hablando?'... Suele haber un hálito de parquedad reflexiva a la hora de pensar el potencial transformador del arte, o mejor, 
de lo estético. Todo cambia, pero ese 'todo' está a cierta distancia presuntamente objetiva que como investigador soy capaz de ver. Este ver no se ubica en el mismo plano que la mirada de gato, es el ver que desoculta un campo y se complace en un rigor científico. Pero, si nos dejamos seducir por la invitación a la relacionalidad modal, el ver ya no es una opción: hay de atreverse a dejarse mirar cara a cara por esa desnudez de gato, esto es: el encuentro con la obra, con sus cucharas y demás cubiertos, sensibilidades, obsesiones, conflictos internos y externos al arte no se deslinda del yo que entra a asociar estos modos; antes bien, se instala en ese plano de la performatividad de sí mismo en el que puedo o no, efectivamente, ser alterado $y$ asumido en este mundo intermodal.

Habría que aceptar que el "discurso del analista", siguiendo el propio diamante de Lacan (2008), no solo permite extraer las relaciones de dominación y goce que se entrelazan y confrontan al "discurso del amo", sino que de hecho es una posición discursiva que produce y transforma al sujeto en "analista". Precisamente el encuentro con la obra en lo estético, con su invitación al extrañamiento, evidenciado en su juego con lo más cotidiano de la experiencia - los cubiertos-, demanda un saber que no puede emerger si no se acepta, a la vez, que esa cosa también me mira: la obra hecha saber compone una mirada que transforma, conforme a mis recursos y disposiciones, el campo efectivo del propio pensar y del investigador que puede mirar. Como todo antropólogo sabe, la reflexividad de la etnografía no yace en ir, ver y contar, sino en dejarse interpelar por el mundo y hacer conocimiento con él. Asimismo, la teoría estética que trama esta modalidad (sin saber a quién) debe estar abierta a reconocer tanto los términos materiales de la experiencia estética, como los términos axiológicos que "están ahí, disponibles para la plasmación, son parte del mundo dado a cualquiera" (Claramonte, 2016, p. 269). Hay que aceptar el riesgo de exponerse a quedar en medio del fuego cruzado entre lo repertorial y lo disposicional para que, como investigador, sea posible dar cuenta del paisaje en el que uno mismo está inscrito y, a la vez, sea posible que el propio acto de exposición se convierta en un acto de creación en el orden del saber estético. Lo que hay aquí es otra forma de equilibrio dinámico que necesariamente hace parte de lo estético y que se requiere para poder producir una teoría estética que, como recuerda Claramonte, debe poner en relación la repertorialidad de lo artístico (teoría de la productividad artística), la disposicionalidad de lo estético (teoría de la sensibilidad estética) y lo complexo de lo cismundano (teoría de los dos anteriores) (2016, p. 121). Pero el elemento que, a la luz de la obra de Bursztyn, atraviesa estas tres dimensiones de una teoría estética es la relación entre el objeto hecho obra y la experiencia del sujeto que entra, a la vez, a ser perturbación y consolidador de sentido, a hacer parte de lo que mira y a dejarse mirar por el arte.

\section{Referencias}

Bertalanffy, L. v. (1989). Teoría general de los sistemas. México: FCE.

Bourdieu, P. (1999). Meditaciones Pascalianas. Barcelona: Anagrama.

Carroll, N. (1999). Philosophy of art. A contemporary introduction. NY: Routledge.

Claramonte, J. (2016). Estética modal. Madrid: Tecnos. . (2007). Procomún y arte, en Estética

y teoría del arte. Jordi Claramonte. Escritos inéditos. Disponible en: http://jordiclaramonte.blogspot. com/2007/09/procomun-y-arte.html

Crown, T. (2001). El esplendor de los sesenta. El arte americano y europeo en la era de la rebeldía 1955-1969. Madrid: Akal.

Danto, A. C. (1964). The artworld. The journal of philosophy, 61(19), 571-584. https://doi. org/10.2307/2022937

Deleuze, G., \& Guattari, F. (2006). Mil mesetas. Capitalismo y esquizofrenia. Valencia: Pre-Textos.

Dickie, G. (1997). The art circle. Chicago: Chicago Spectrum Press.

Elias, N. (2011). El proceso de la civilización. Madrid: FCE.

Hodge, S. (2014). Por qué un niño de cinco años no pudo haber hecho esto. México: Altea.

Lacan, J. (2008). Seminario XVII El reverso del psicoanálisis. Buenos Aires: 2008.

Osorio, A. (18 de Enero de 2010). Feliza Bursztyn, una obra. RE-VISTA. Medellín, Nro. 8 Vol. 2. 1982. Pág. 12, 
en Esfera Pública. Disponible en: https://esferapublica. org/nfblog/feliza-bursztyn-una-obra/

Pineda Repizzo, A. F. (2011). Terapia a la pregunta filosófica: ¿qué es el arte?. Calle 14 Revista De investigación En El Campo Del Arte, 5(7), 62-77. https:// doi.org/10.14483/udistrital.jour.c14.2011.2.a06

Ramírez, M. C. (2004). Vital structures. The constructive nexus in South America. En M. C. Ramírez, \& H. Ólea, Inverted utopias. Avant-Garde Art in Latin America (págs. 191-201). Houston: Yale University Press.

Rancière, J. (2009). La división de lo sensible: estética y política. Centro de Estudios Visuales de Chile: Jacques Rancière, Señas y Reseñas. Disponible en: http://www. centroestudiosvisuales.cl

Zizek, S. (2011). El acoso de las fantasías. Madrid: Akal. 